\title{
Challenges and strategies when mapping local ecological knowledge in the Canadian Arctic: the importance of defining the geographic limits of participants' common areas of observations
}

\author{
Laura M. Martinez-Levasseur ${ }^{1,2} \cdot$ Chris M. Furgal $^{2}\left(\right.$ Mid $^{2}$ Mike O. Hammill $^{3}$. \\ Gary Burness ${ }^{1}$
}

Received: 16 October 2015 / Revised: 25 August 2016 / Accepted: 22 December 2016 / Published online: 4 March 2017

(C) The Author(s) 2017. This article is published with open access at Springerlink.com

\begin{abstract}
Traditional and local ecological knowledge (TEK/LEK) are important sources of information for wildlife conservation. However, there are often limitations and biases in the TEK/LEK methods used. In this study, we examined and implemented strategies to address the limitations and biases we identified while analyzing the mapped observations collected from 27 interviews as part of a larger project on walruses in Nunavik (Canadian Arctic). Our main objectives were to: (1) examine the importance of recording participants' temporal and spatial limits of observations; (2) identify the factors influencing the quantity and diversity of mapped observations; (3) study the importance of documenting approximate numbers of animals observed; (4) examine the importance of gathering and presenting data at consistent and standardized spatial scales. We found that by adding to maps the geographic limits of participants' common areas of observations, we were able to distinguish areas that hunters typically visited and did not see walruses, from areas that hunters never visited. Furthermore, we showed that the variability in the quantity of mapped observations was explained by the community of residence and average number of hunting
\end{abstract}

Laura M. Martinez-Levasseur

lmmartinezlevasseur@gmail.com

Chris M. Furgal

chrisfurgal@trentu.ca

1 Department of Biology, Trent University, Peterborough, ON K9J 7B8, Canada

2 Departments of Indigenous Studies and Environmental Resource Studies/Sciences, Trent University, Peterborough, ON K9J 7B8, Canada

3 Maurice Lamontagne Institute, Fisheries and Oceans Canada, Mont-Joli, QC G5H 3Z4, Canada trips per participant, but not by participant age. Finally, although careful adjustments and standardization would be needed, we showed that by having an estimate of the number of walruses observed per area drawn, it would be possible to estimate mean local abundances of walruses. We hope this careful examination of TEK/LEK methods will help to increase confidence in these datasets as a valuable source of knowledge for wildlife conservation.

Keywords Traditional and local ecological knowledge . Limitations and biases - Participant mapping process . Atlantic walruses . Odobenus rosmarus rosmarus . Canadian Arctic

\section{Introduction}

Due to rapid environmental changes, there is a pressing need to create reliable long-term datasets on wildlife ecology. Traditional and local ecological knowledge (TEK/ LEK, defined in methods), gathered through interviews with harvesters living in close relationship with wildlife, is a key source of information (Huntington 2011; Pardode-Santayana and Macía 2015). The resulting TEK/LEK qualitative database can provide information on aspects of wildlife ecology, which are not always targeted by the scientific community, or which are beyond the reach of traditional scientific observations, particularly for wide ranging species living in remote environments (Mallory et al. 2003; Huntington 2011; Service et al. 2014). For example, initial population estimates of 2000-3000 bowhead whales (Balaena mysticetus) obtained from visual coastal counts, increased to 6000-8000 after native Alaskans pointed out the inaccuracy of the census method, which did not take into account diving whales 
and changes in whale migratory routes due to movement of the ice pack (Huntington 2000). Further, local knowledge from residents of three high Arctic communities in eastern Canada reported broad population declines of the ivory gull (Pagophila eburnea), an issue previously not fully recognized by the scientific community (Mallory et al. 2003). It has become increasingly appreciated by the scientific community that TEK/LEK has enhanced our understanding of the ecology of species, and is valuable for their future management (Service et al. 2014; Pardo-de-Santayana and Macía 2015). However, it is important to note that there are often limitations and biases in the methods commonly used to gather, analyze and represent TEK/LEK that can not only jeopardize the reliability and validity of the data collected, but potentially result in negative impacts for wildlife populations (Nadasdy 2003; Gilchrist et al. 2005).

Numerous studies have examined the reliability of the data gathered through TEK/LEK research methods. For example, several studies have reported that the benefits of LEK differed from one species to the other. For example, Gilchrist et al. (2005) demonstrated that the benefits of LEK were highest for marine bird species with which local peoples had greater familiarity through harvest or year-round contact. Another study showed that while the incorporation of TEK on Arctic fox (Vulpes lagopus) increased the spatial and temporal observational scales of current scientific datasets, this did not occur for snow geese (Chen caerulescens atlantica) (Gagnon and Berteaux 2009). Furthermore, most studies have reported that the quantity, diversity and accuracy of LEK data provided vary among interviewees (Davis and Wagner 2003; Gilchrist et al. 2005). Although approaches to limit the reported inter-individual variation in LEK accuracy have been proposed (e.g., careful selection of the participating communities and interviewees) (Davis and Wagner 2003; Gilchrist et al. 2005; Gadamus and Raymond-Yakoubian 2015), this has not been formally studied. Additionally, although attention has been given to the critical examination of the mapping methods often used in TEK/LEK research (Gagnon and Berteaux 2009; Tobias 2009; Kowalchuk and Kuhn 2012), it is recognized that the impacts of some TEK/LEK mapping methods on the resulting data continue to produce biases (e.g., bias toward coastal observations) (Hartwig 2009; Kowalchuk and Kuhn 2012). For example, Lewis et al. (2009) showed that while $76 \%$ of telemetry data for 30 belugas (Delphinapterus leucas) were located $15 \mathrm{~km}$ offshore, only $17 \%$ of TEK data indicated offshore locations. Although limitations and biases in TEK/LEK data and methods have been reported in several studies, we have not found any previous studies presenting analyses that statistically demonstrate the biases created by some TEK/LEK methods, and, in general, clear solutions have rarely been provided.
In this study, we examined and implemented strategies to address the limitations and biases we identified while analyzing the mapped observations collected from 27 interviews as part of a larger project on Atlantic walruses, Odobenus rosmarus rosmarus, in Nunavik (Canadian Arctic). Our objectives were to: (1) examine the importance of recording participants' temporal and spatial limits of observations; (2) identify the factors influencing the quantity and diversity of mapped observations; (3) study the importance of documenting approximate numbers of animals observed; (4) examine the importance of gathering and presenting data at consistent and standardized spatial scales.

\section{Methods}

This study is part of a larger project, "Walruses and population health in Nunavik, drawing upon both scientific methods and local ecological knowledge", which was approved by the four participating Inuit communities and their local Hunting Fishing and Trapping Associations, Northern Villages and Landholding Corporations (March-September 2013), the Nunavik Marine Region Wildlife Board (December 2012) and by Trent University Research Ethics Board (December 2012) and the Trent Aboriginal Education Council (February 2013). The corresponding methods used, including the selection of participants, the development of the questionnaire and interview support guides, as well as the interviews and internal validation workshops, followed the standards of the social research methods used to document local and traditional knowledge (Huntington 2000; Seidman 2006; Creswell 2009; Furgal and Laing 2012). Some results of the larger project have been published in April 2016 (Martinez-Levasseur et al. 2016). Limitations and biases discussed in the current study were identified while analyzing the mapped observations collected as part of the larger project.

\section{Defining local ecological knowledge}

Although local ecological knowledge held by Indigenous peoples is often referred as traditional ecological knowledge, or TEK (Berkes et al. 2000; Huntington 2011), we concur with previous authors (Davis and Wagner 2003; Gilchrist et al. 2005; Furgal and Laing 2012) that TEK may not be the most appropriate term to describe the information presented in studies that report solely observational data acquired over the lifetime of participants. Furthermore, detailed ecological information has been reported to be held by non-Indigenous groups around the world (Anadón et al. 2008; Azzurro et al. 2011; Turvey et al. 2013). As we were reporting observations of participants during their lifetime and included one non-Inuk hunter recognized for his 
knowledge and activity in walrus hunts, we used the term local ecological knowledge, or LEK, as used elsewhere in the literature (Gilchrist et al. 2005; Azzurro et al. 2011), to describe the knowledge documented in our study. However, when referring to other studies, we used the term reported by the authors of those articles. Finally, it is important to acknowledge that although putting a term on the knowledge we documented is useful as general reference, any such label is a non-Indigenous term created to identify another group's knowledge (Laidler 2006).

\section{LEK data collection and validation: larger project}

\section{Area of study and participant selection}

The communities of Inukjuak, Ivujivik, Quaqtaq and Kangiqsualujjuaq in Nunavik (Northern Quebec, Canada; Fig. 1) were selected due to their active participation in walrus hunting (Larrat et al. 2012), their wide geographic distribution representing the entire range of walruses in Nunavik (Stewart 2008) and their interest in Inuit knowledge-science research as evidenced by active participation in previous projects (Chris Furgal, unpublished information). Ten to 15 walrus hunters, recognized for their knowledge and activity in walrus hunts by the communities and the local Hunters Fishers and Trappers Associations, were identified in each community and invited to participate in the study during our first visit to communities (March and June 2013). Because women are generally involved in walrus hunting and meat preparation, they were also invited to participate. Note that although the communities selected are based in Nunavik, participants provided information on observations of walruses in both Nunavik and Nunavut (as many islands around Nunavik are technically part of the territory of Nunavut).

\section{Interviews and spatial data collection}

Semi-directive interviews were conducted during a second trip (June and September 2013) with the help of EnglishInuktitut interpreters/translators. The interviews aimed to document knowledge and observed changes in walrus ecology and distribution as well as changes in walrus health (a copy of the interview guide is available from the corresponding author). The themes of the interview were: (1) walrus hunting methods; (2) walrus distribution and movement; (3) walrus health, including the potential effect of solar radiation on walruses; (4) walrus feeding and reproduction, and (5) walruses as country food. To gather spatial data of walruses during the interviews (e.g., where walruses have been observed, which migration routes walruses have been observed taking), we created ten base maps in both English and Inuktitut of the areas surrounding participating

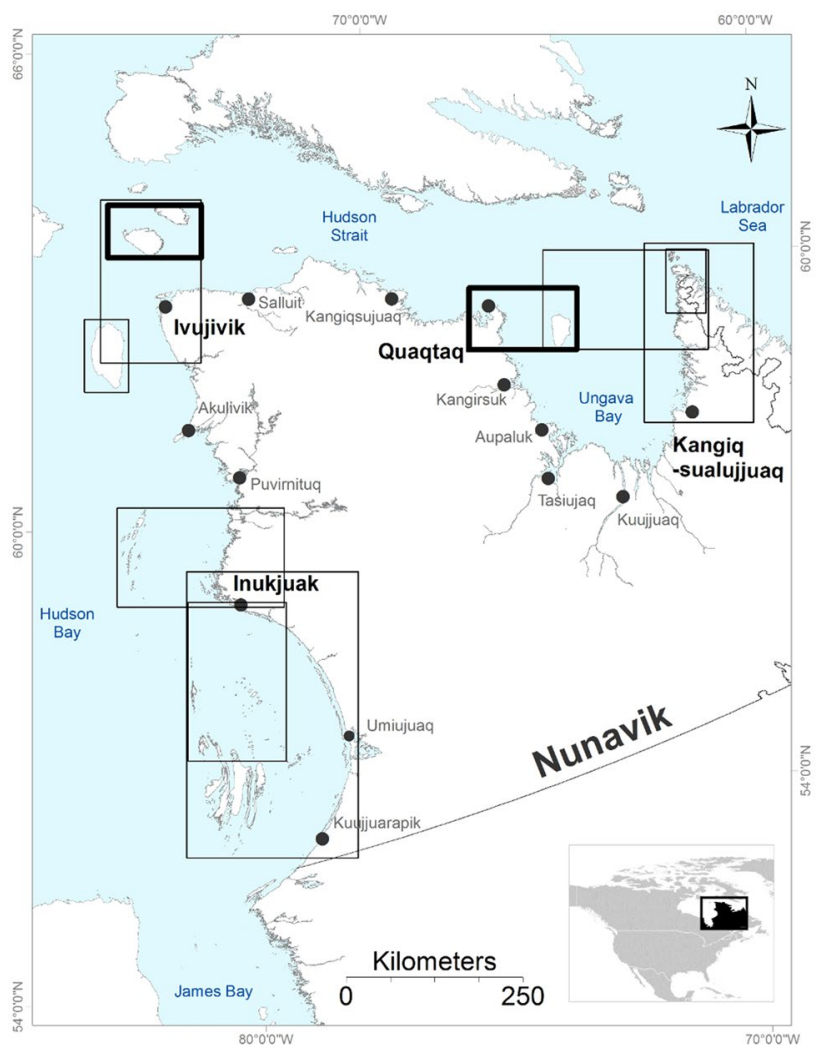

Fig. 1 Map of Nunavik (Northern Quebec, Canada), showing the four communities involved in the project (Inukjuak, Ivujivik, Quaqtaq and Kangiqsualujjuaq). The quadrat shows the limits of the base maps used to document local knowledge on Atlantic walruses (Odobenus rosmarus rosmarus) during interviews. The two quadrats drawn with thicker lines, corresponding to the area of Nottingham \& Salisbury Islands (north of Ivujivik) and the area of Quaqtaq, correspond to areas used in the case studies presented in this paper (objectives 1 and 4). Map created using the geographic information system software ArcMap 10.1 (Digital vector datasets: RNCan-National Topographic Database)

communities using the geographic information system software ArcMap 10.1 (Digital vector datasets: RNCanNational Topographic Database; Fig. 1). The scale of the maps varied between 1:100,000 and 1:450,000, depending on the extent of walrus hunting areas provided by the local Hunters Fishers and Trappers Associations during our first visit. A regional map (scale: 1:2,000,000) was also created. Note that participants could provide information on maps of different scales and on maps corresponding to different areas within Nunavik. The mapping process of the interviews followed guidelines previously described (Tobias 2009). Briefly, participants drew points (e.g., walrus kill sites), lines (e.g., walrus migration routes) or polygons (e.g., areas where walruses had been observed) onto transparent plastic overlays that covered base maps. Each point, line or polygon (map features) drawn was attributed an alphanumeric code, which facilitated the reconnection 
of audio-recorded information (i.e., details on each feature) with maps (Tobias 2009). In addition to the data gathered for each participant (e.g., age, gender, residence community, estimated number of hunting trips corresponding to a proxy of the expertise of the participant), for each map feature drawn, attribute data were gathered (e.g., source of observation; date and estimated frequency of observation; details on the walrus observation, such as approximate number of walruses and their activity: feeding, resting, or travelling). Note that each map feature corresponded to a geographic location where walruses had been observed one or more times (e.g., every year for the last 5 years). The date (or period) and the estimated frequency of each observation were recorded as follows: once= only one observation of walruses had been made at that geographic location during the hunter's life; rare=observations made two or three times; sometimes = observations made irregularly but at least three times; frequent $=$ observations made almost every time the location was visited; always = observations made every time the location was visited. Before the interview, the interview guide, as well as the participant consent form and letter of information (summary of the project), were provided to each participant in English or Inuktitut (at the participant's preference).

\section{Qualitative data analysis and internal validation}

The audio-recorded interviews were transcribed, entered into the qualitative analytical software program NVivo10 (Version 10, 2012), and analyzed using thematic content analyses (core results of interview data will be presented in future manuscripts) (Creswell 2009). The 58 maps created during the interviews were scanned, digitized and analyzed using ArcMap 10.1. The maps created (by season and/or time period) (Gadamus and Raymond-Yakoubian 2015) for internal validation workshops combined the personal knowledge of all participants. To verify and validate the preliminary results, participants were invited to two workshops (one on the qualitative/ quantitative data and one on the mapped observations), which were organized during a third visit to communities (Huntington 2000) in July 2014. At this time the idea of adding participants' common areas of observations to maps was also presented and discussed. The workshops lasted between 2 and $3 \mathrm{~h}$. When a participant disagreed with any information presented corrections were made, but only when the data corresponded to their personal observation and not that of another participant. During the workshop, participants were asked to explain variation in the spatial location and area covered by their data as compared to other participants. The approximate number of walruses observed per area drawn (less than
5 , between 5 and 15 , between 15 and 50 , and more than 50) were also confirmed during validation workshops. For this, we used photographs of walrus groups of different sizes to discuss approximate numbers. Some hunters showed us, for some specific observations, photographs of their own on which we could count together the number of walruses they saw at these specific sites. Only those areas and data (e.g., number of walruses) that could be validated during workshops were included in the analyses of the current study. These workshops not only allowed the validation or correction of our interpretation of the data, but also kept participants informed about the progress of the study. Finally, following further analyses, results were presented to each community during a final trip (Huntington 2000) in March 2015. This final trip was used to share final results and distribute corresponding reports with the participants and their communities.

\section{Dataset}

In total, 33 local walrus hunters and Elders participated in the study, corresponding to $55 \%$ of the potential participants identified by the local Hunters Fishers and Trappers Associations during the first visit. In each community, we interviewed between 7 and 10 participants (10, 8, 8 and 7 participants in, respectively, Quaqtaq, Ivujivik, Kangiqsualujjuaq and Inukjuak), ranging from 35 to 85 years of age. Among the 33 interviewees four women were included. Of the participants interviewed, $69 \%$ subsequently participated in the validation workshops. In the analyses, only direct personal knowledge/observations were included. The seasons were defined and confirmed by participants as: fall (September-mid-December), winter (end December-April), spring (May-mid-June) and summer (end June-August). Two time periods in the history of walrus observations and hunting in Nunavik were demarcated in the analyses and presentations of results: 1940s-1990s and 2000s-2010s. For the current study, but not for the larger study, women were excluded from the statistical analyses due to their low number $(n=4)$, as well as two Elders for whom involvement in walrus hunting was unclear. For the analyses of the current study, participants $(n=27$; only men with experience in walrus hunting; Table 1) were divided into four age groups as follows: $35-55,56-65,66-75$, and 76-85 years old (35-45 and 46-55 years old were combined in one group to balance sample sizes for analyses). Participants were also divided in two groups according to the number of hunting trips they performed during their life (less than 10 trips at the moment of the interview, more than 10 trips; Table 1). 
Table 1 Dataset

\begin{tabular}{lllllllr}
\hline & \multicolumn{2}{l}{ Age group } & & & \multicolumn{2}{c}{$\begin{array}{l}\text { Number of hunt- } \\
\text { ing trips }\end{array}$} \\
\cline { 2 - 6 } \cline { 3 - 6 } & $35-55$ & $56-65$ & $66-75$ & $76-85$ & & $<10$ & $\geq 10$ \\
\hline Quaqtaq $(n=7)$ & 4 & 0 & 1 & 2 & 2 & 5 \\
Ivujivik $(n=8)$ & 2 & 3 & 2 & 1 & 1 & 7 \\
Inukjuak $(n=5)$ & 1 & 0 & 4 & 0 & 2 & 3 \\
Kangiqsualujjuaq $(n=7)$ & 0 & 4 & 2 & 1 & 5 & 2 \\
Total $(n=27)$ & 7 & 7 & 9 & 4 & 10 & 17 \\
\hline
\end{tabular}

For the analyses of the current study, participants ( $n=27$; only men with experience in walrus hunting) were divided into four age groups as follows: $35-55,56-65,66-75$, and 76-85 years old (35-45 and 46-55 years old were combined in one group to balance sample sizes for analysis). Participants were also divided in two groups according to the number of hunting trips they performed during their life (less than 10 trips at the moment of the interview, more than 10 trips)

\section{Objective 1: examine the importance of recording participants' temporal and spatial limits of observations}

By not initially documenting the geographic limits of participants' regular activities at sea during the interviews (e.g., how far from the coast hunters generally travel), we noticed that a potential spatial bias towards the coast of the mapped walrus observations had been created, as previously reported for other species (Hartwig 2009; Lewis et al. 2009; Kowalchuk and Kuhn 2012). Furthermore, we realized that the mapped areas corresponding to walrus observations excluded the areas where hunters typically go but do not see walruses, as well as the areas where hunters reported never going. In an attempt to address this bias toward coastal observations, and the bias that walruses are absent from certain areas, we asked participants present at the group validation workshops to draw the areas they were familiar with and for which they had direct observational knowledge and experience. We called these areas "participants' common areas of observations". Briefly, the geographic limits of participants' common areas of observations were: (1) community specific (generally drawn as a group; if participants provided their personal geographic limits, the furthest limit that includes all the limits drawn by participants was kept); (2) season specific, particularly as hunter activity at sea changes throughout the year; (3) time-period specific (e.g., 1940s-1990s) unless there was no change in observations of the species over time. It is important to note that participants' common areas of observations did not always correspond to the hunting areas of the targeted species (e.g., although walruses were not hunted in winter, they could be observed by local hunters harvesting seals in winter, thus common areas of observations for winter generally corresponded to winter seal hunting areas). Two case studies were used to examine the importance of recording the geographic limits of participants' common areas of observations when mapping local ecological knowledge of walruses in Nunavik.

Case study 1: local knowledge from eight Ivujivik participants was documented on walrus observations for the area of Nottingham \& Salisbury Islands (Hudson Strait, Nunavut, Canada; Fig. 1). Following the interviews, maps including the observations of the eight participants were created by time period (1940s-1990s and 2000s-2010s).

Case study 2: local knowledge from seven Quaqtaq participants was documented on walrus migration routes around their community (Fig. 1). During the interviews, participants explained that walruses use the same migration routes in the fall (specifically between November and beginning of December) as in the summer (end June to mid-July). However, participants also explained that boating activities were rare after September due to bad weather conditions. In order to explore this contradiction (i.e., how participants could provide observations on walrus migration routes in the fall if fall hunting expeditions were rare), two maps were created, one for the summer and one for the fall. Both were presented and discussed during the Quaqtaq group validation workshop.

\section{Objective 2: identify the factors influencing the quantity and diversity of mapped observations}

We explored which variables, defined as factors, amongst age group (35-55, 56-65, 66-75, 76-85 years old), total number of hunting trips performed (less than 10 trips at the moment of the interview, more than 10 trips), and community of residence (Inukjuak, Ivujivik, Quaqtaq, Kangiqsualujjuaq), best explained the variability in the quantity and diversity of mapped observations. The quantity of mapped observations corresponded to the total number of walrus observations drawn on maps (sum of points and polygons). The diversity of mapped observations corresponded to the total number of walrus observations provided with detailed information (e.g., walrus 
activity such as feeding, resting, or travelling). The quantity and diversity of mapped observations were calculated for each participant ( $n=27$; only men with experience in walrus hunting).

\section{Objective 3: study the importance of documenting approximate numbers of animals observed}

During interviews participants drew on maps areas where they have observed walruses (hereafter called walrus area). They also reported the approximate number of walruses observed in those locations. Walrus areas drawn varied in size (from less than $1 \mathrm{~km}^{2}$ to over $100 \mathrm{~km}^{2}$ ). The variation can create a perception by readers and those interacting with LEK generated maps that larger walrus areas include a greater number of walruses. To explore the relationship between the sizes of walrus areas drawn and walrus numbers observed, we first measured the size of 117 walrus areas (in $\mathrm{km}^{2}$ ) drawn that could be validated during the workshops. We then used ArcGIS tools to compare the size of walrus areas with the approximate number of walruses observed and reported by participants $(<5,5-15,15-50$, $>50$ ). Only validated features that were drawn on local maps (between 1:100,000 and 1:280,000) were included in the analyses.

\section{Objective 4: examine the importance of gathering and presenting data at consistent and standardized spatial scales}

Hunters were asked to draw the routes animals follow when travelling through or near their community (Mymrin et al. 1999; Lewis et al. 2009) on maps of different scales. Large-scale maps (covering a small geographic area, but with greater detail) provide participants the opportunity to be more precise with their lines and thus can give a more accurate estimate of how far offshore animals are found. To examine the potential bias when creating digital maps from data collected on maps at different scales (e.g., when documenting migration routes), we first selected a region where walrus migration routes were drawn at both local and regional scales (area of Quaqtaq with scale maps at 1:170,000 and 1:2,000,000; Figs. 1, 5a). We then selected a single location (Nuvuk point; Fig. 5a) and drew a vertical line from that point across all drawn walrus migration lines and used ArcGIS tools to calculate distances between the coast (Nuvuk point) and migration routes drawn (in total 17 distances were measured in $\mathrm{km}$ ). We predicted that migration routes drawn on the regional map $(1: 2,000,000)$ would be significantly further from the coast than those drawn on the local map $(1: 170,000)$.

\section{Statistical analyses}

All statistical analyses were performed in the free software R 3.0.1 (Ihaka and Gentleman 1996; R Development Core Team 2015). To identify the factors influencing the quantity and diversity of mapped observations (objective 2), we created linear models and used a top down strategy to define the minimal adequate model. Briefly, a variable was retained in the model only if it caused a significant increase in deviance when removed from the current model, which was assessed using backwards step-wise elimination tests (Fisher-tests) (Crawley 2007). To explore the relationship between the size of walrus areas drawn and walrus numbers (objective 3), we ran an ANOVA by using linear regression analysis $(\mathrm{lm})$, which allowed us to control for potential variation amongst participants and amongst maps of different scales (Crawley 2007; R Development Core Team 2015). The distances from the coast of walrus migrations routes drawn at different map scales (objective 4) were compared using a non-parametric Wilcoxon test. The package gvlma (global validation of the linear model assumptions) was used to confirm that the models' assumptions were respected (Pena and Slate 2006). For each explanatory variable (also called independent variable) the degree of freedom $(d f)$, the Fisher value $(F)$ and $p$ value $(p)$ were reported. The results provided for the model are the adjusted $R^{2}$ and the $p$ value. $p$ values were considered significant when $\leq 0.05$.

\section{Results}

\section{Objective 1: examine the importance of recording participants' temporal and spatial limits of observations}

\section{Case study 1: defining participants' common areas of observations reduces geographical and temporal biases}

Comparisons of maps, with and without participants' common areas of observations explicitly identified, resulted in different perceived patterns of walrus distribution. Figure 2a (without common areas of observations) showed that between 1940s and 1990s walruses were mostly concentrated within $5 \mathrm{~km}$ of the coast and that walruses were absent from the north and east of Salisbury Island. Figure $2 b$ (with common areas of observations for the same time period) revealed that in fact hunters mostly travelled within $5 \mathrm{~km}$ of the coast and that the north and east of Salisbury Island were not visited by hunters (i.e., absence of data). Figure 2a, c (without common areas of observations) showed that walruses have changed 


\section{Without common areas of observations}
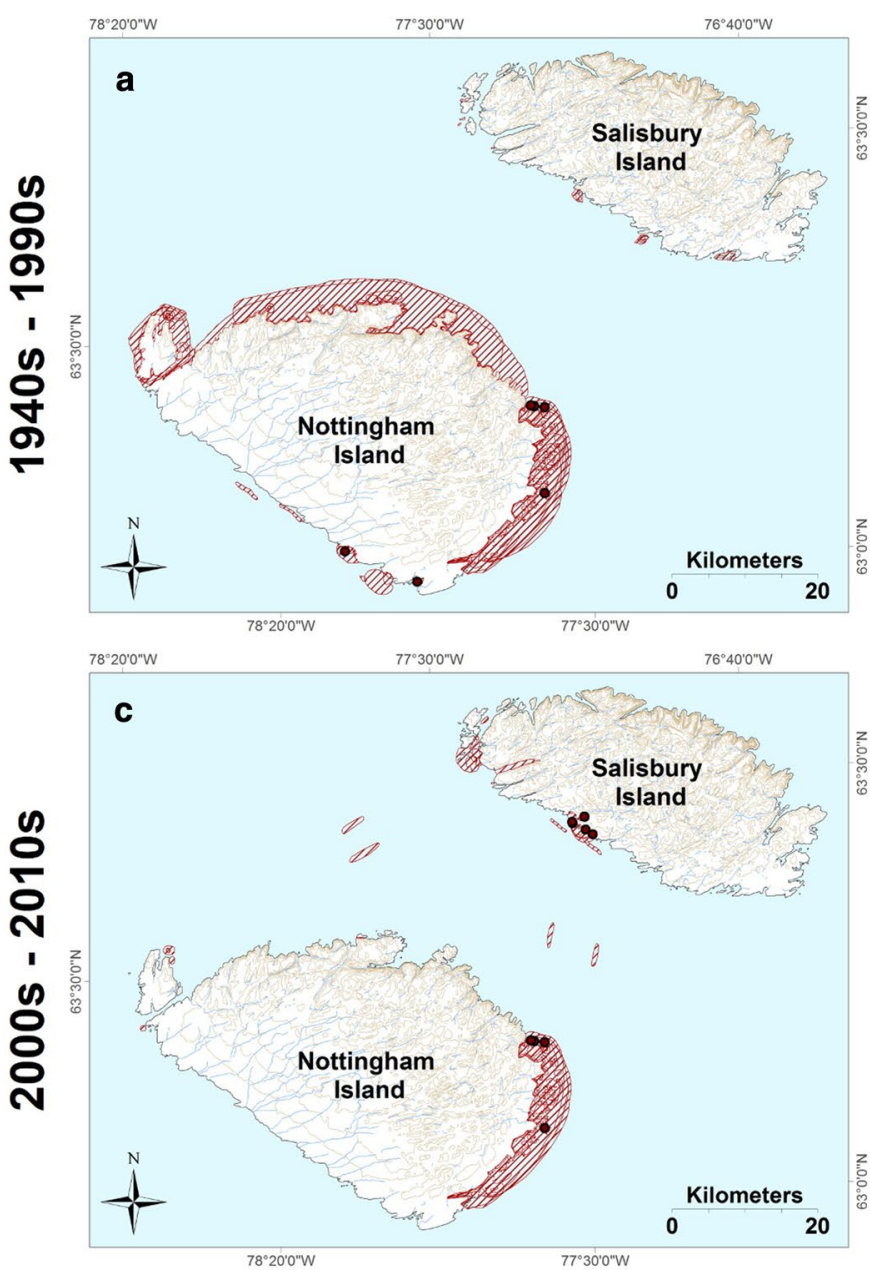

Fig. 2 The importance of recording and mapping participants' common areas of observations. Local knowledge and observations (from eight Ivujivik participants interviewed in 2013) on Atlantic walruses, Odobenus rosmarus rosmarus, around Nottingham and Salisbury Islands (North of Nunavik, Quebec, Canada) for the fall in 1940s-1990s (upper figures) and in 2000s-2010s (lower figures).

locations between the 1940s-1990s and the 2000s-2010s. Figure $2 b$, d (with common areas of observations) revealed that hunters have in fact changed their common areas of observations (in this case walrus hunting locations). Finally, few observations of walruses were made outside the participants' common areas of observations (e.g., mapped observations between Salisbury and Nottingham Islands on Fig. 2c, d). When participants were asked about walruses observed outside their common areas of observations, they explained that they sometimes saw one or two walruses swimming between the islands while crossing by boat, but they reported those positions as inexacts.

\section{With common areas of observations}
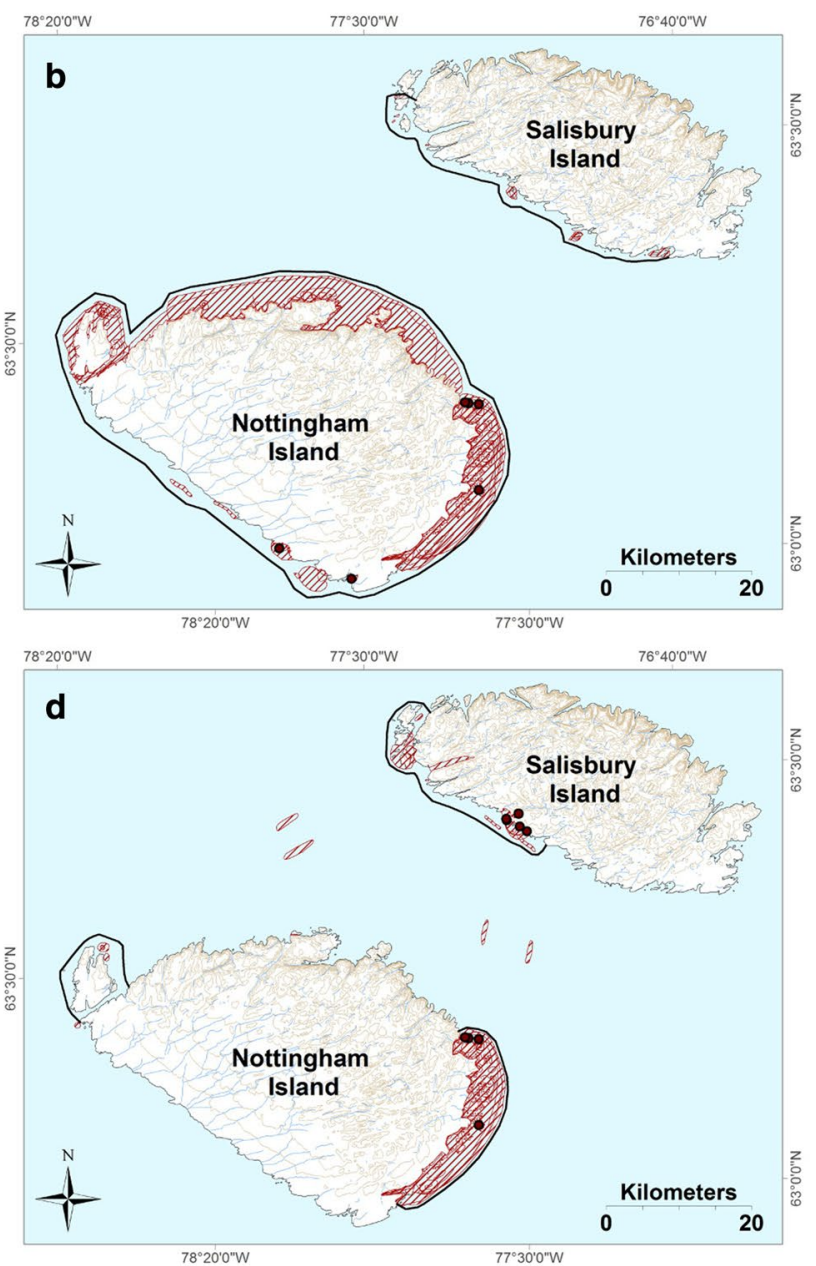

Areas with striped lines correspond to the area where walruses have been observed and reported. Points correspond to walrus observation sites. a Maps without the participants' common areas of observations explicitly identified. b Maps with the participants' common areas of observations identified (black thick line)

\section{Case study 2: mapping participants' common areas} of observations reduces potential seasonal bias

During internal validation workshops it was clarified that observations of walruses in the fall were rare, and mostly occurred around the community of Quaqtaq (Fig. 3). At the end of the validation discussion, participants asked to have the information they provided during interviews on fall migration routes removed from the maps, as these routes fell outside of their common areas of observations. 
Fig. 3 Defining areas of knowledge reduces potential seasonal bias. The figure shows the migration routes (dotted line) of Atlantic walruses, Odobenus rosmarus rosmarus, drawn for the fall by seven participants interviewed in Quaqtaq (Nunavik, Northern Quebec, Canada) in 2013. These routes were subsequently removed from the data after putting the geographic limits of participants' common areas of observations (thick black line) on the map (which was restricted to Quaqtaq in the fall due to inclement weather)

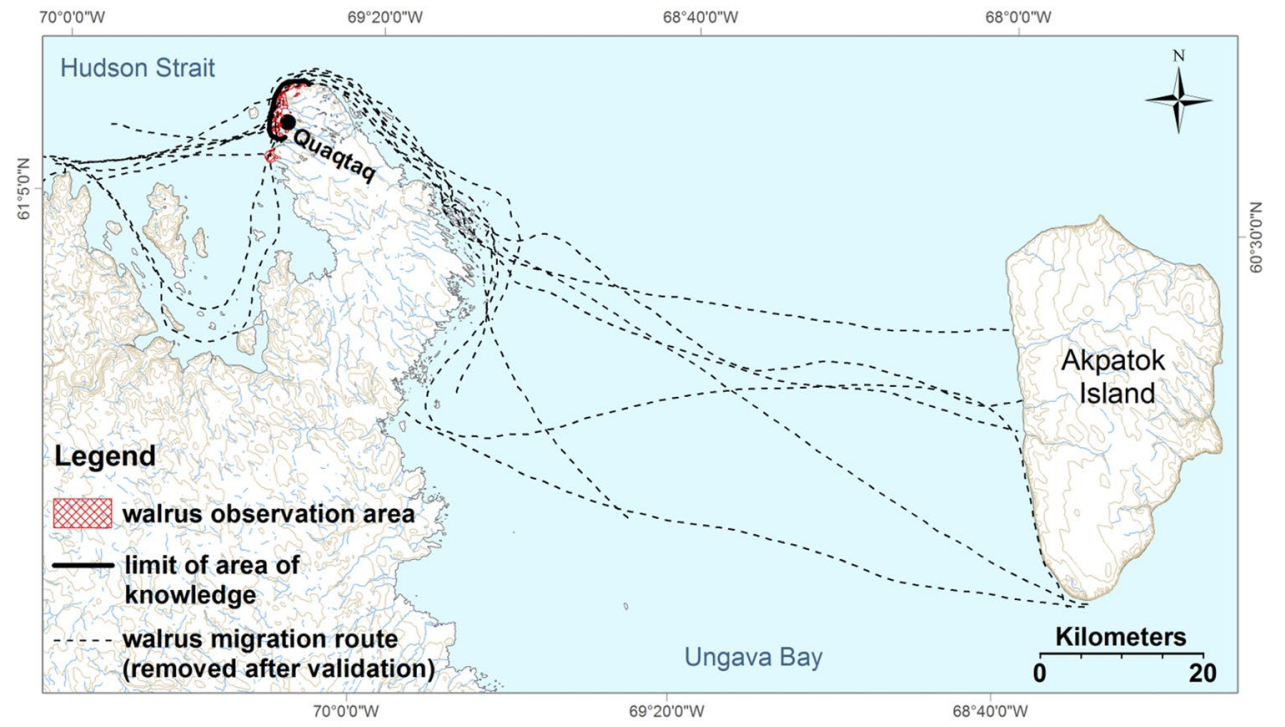

\section{Objective 2: identify the factors influencing the quantity and diversity of mapped observations}

We found that while the community and the number of hunting trips explained the variability in the quantity and diversity of mapped observations (Table 2), age did not (backward step-wise deletion: $F=1.19, p=0.35$ for the model on quantity and $F=26, p=0.85$ for the model on diversity). Participants with more experience in walrus hunting (corresponding to those who have been walrus hunting more than ten times during their life) provided greater quantity and diversity of mapped observations (Fig. 4b). Participants from Ivujivik provided greater quantity and diversity of mapped observations (number of walrus observations provided with detailed information; e.g., walrus activity such as feeding, resting, or travelling) compared to participants from other communities (Fig. 4a).

\section{Objective 3: study the importance of documenting approximate numbers of animals observed}

Larger geographic areas did not contain larger numbers of walruses $(p=0.32$, Table 3$)$. The model highlighted the importance of participant identity in the sizes of the walrus areas drawn (i.e., inter-participant variability; $p<0.0001$, Table 3). Variation among participants in the sizes of the walrus areas drawn was also observed for participants using the same hunting areas $(n=90$ walrus areas drawn at $1: 150,000$ by six participants from Ivujivik; Kruskal-Wallis: $\chi^{2}=14.57, d f=5, p=0.01$ ). During the internal validation workshops, when presenting the maps showing different features drawn by all participants, there were no comments related to the differences in area sizes drawn by different participants. When directly asking participants who drew disproportionately larger areas
Table 2 Factors influencing the quantity and diversity of mapped observations of Atlantic walruses, Odobenus rosmarus rosmarus, from Nunavik, Northern Quebec, Canada $(n=27$ participants; men only and those with experience in walrus hunting)

\begin{tabular}{lllrc}
\hline Response variable & Explanatory variable & $d f$ & $F$ & $p$ \\
\hline Quantity & Community identity & 3 & 26.96 & $<0.0001$ \\
& Number of hunting trips & 1 & 32.77 & $<0.0001$ \\
& Interaction (community and hunt trips number) & 3 & 5.45 & 0.008 \\
Diversity & Community identity & 3 & 29.38 & $<0.0001$ \\
& Number of hunting trips & 1 & 20.23 & 0.0002 \\
& Interaction (community and hunt trips number) & 3 & 3.67 & 0.03 \\
\hline
\end{tabular}

The table presents the results of the minimal adequate model fitting the data on quantity and diversity of mapped observations. Explanatory variables were defined as factors and retained in the minimal model: community of residence (Inukjuak, Ivujivik, Quaqtaq, Kangiqsualujjuaq), number of hunting trips participated in $(<10$ trips at the moment of the interview, $>10$ trips $)$, and the interaction between both factors. Models' assumptions were considered acceptable (global stat of gvlma: $p>0.05$ ) after removing one outlier, which corresponded to a participant for which the number of hunting trips was not properly recorded $(n=26)$. The adjusted R2 for the models were 0.83 and 0.82 , respectively, for the model on quantity (upper part) and diversity (lower part). The table provides the results of the ANOVA (model) including degree of freedom $(d f)$, Fisher value $(F)$ and $p$ value $(p)$ 

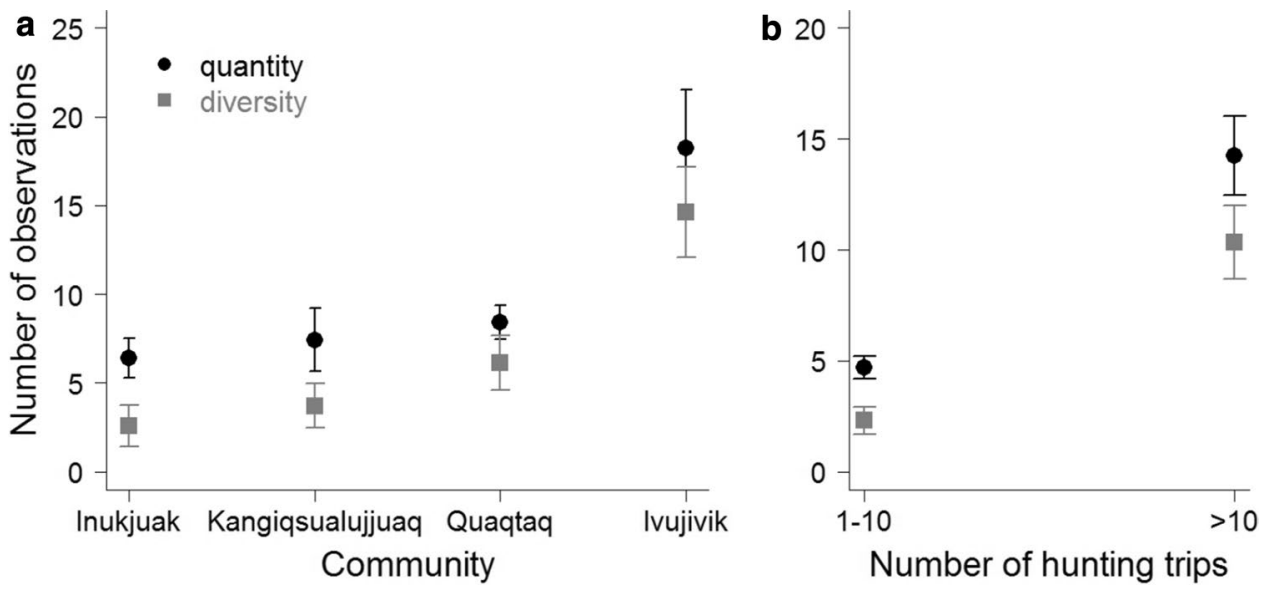

Fig. 4 Variation in the quantity and diversity of mapped observations by community and participants' level of expertise on Atlantic walruses, Odobenus rosmarus rosmarus ( $n=27$ participants, men only with experience in walrus hunting). a Number of mapped observations per community $(n=5,7,7$ and 8 participants, respec-

Table 3 Results from a model testing whether the sizes of the areas where Atlantic walruses (Odobenus rosmarus rosmarus) from Nunavik (Northern Quebec, Canada), have been observed are proportional to the approximate numbers of walruses observed ( $n=117$ polygons)

\begin{tabular}{lrll}
\hline Explanatory variable & $d f$ & $F$ & $p$ \\
\hline Walrus number & 3 & 1.20 & 0.32 \\
Participant identity & 19 & 3.51 & $<0.0001$ \\
Map scale & 4 & 2.32 & 0.06 \\
\hline
\end{tabular}

The response variable (area size) was log-transformed. Explanatory variables were defined as factors: approximate number of walruses with four levels $(<5,5-15,15-50,>50)$; participant (with 20 levels; the lower number of participants is due to the fact that not all participants provided walrus number approximates; only men with experience in walrus hunting were included); map scale with five levels $(100,150,170,250,280 \mathrm{~K})$. The adjusted $R^{2}$ for the model was 0.32 . The table provides the results of the ANOVA (model) including degree of freedom $(d f)$, FISHER value $(F)$ and $p$ value $(p)$

compared to others, they explained: (1) it was an error (and in that case the participant re-drew the area); (2) the area was drawn that large because it enclosed all the areas where walruses have been observed (and in that case the participant was asked to draw each area where walruses have been observed and an annotation was added to the limit of the large area drawn); or (3) it was not an error (in that case we verified that it was within the geographic limits of the participant common areas of observations). Note that the statistical analyses presented above only used validated mapped observations (i.e., validated walrus areas). tively, for Inukjuak, Kangiqsualujjuaq, Quaqtaq, Ivujivik). b Number of mapped observations by number of hunting trips participated in ( $n=10$ and 17 participants, respectively, for those who have been walrus hunting less and more than 10 times during their life). Bars \pm SE

\section{Objective 4: examine the importance of gathering and presenting data at consistent and standardized spatial scales}

The distances from the coast of walrus migration routes in summer drawn by participants differed significantly between local and regional maps (means $=0.92$ and $4.77 \mathrm{~km}$, respectively, for regional and local maps; Wilcoxon test: $W=7, p=0.02$; Fig. 5). When discussing the variations in the distances from the coast of the walruses migration routes drawn on regional maps compared with those drawn on local maps, participants explained that, although the lines drawn in regional maps are not precise, they provide the general direction taken by walruses during their migration.

\section{Discussion}

Knowing that local ecological knowledge (LEK) studies with a mapping component are increasing in frequency, and are now often required when proposing and assessing the potential impacts of new development projects (e.g., mining) (Wiles et al. 1999; Ellis 2005), there is a pressing need to increase rigor in the methods used to document and map LEK. In this study, we explored potential biases and limitations and examined strategies to address them in mapped observations collected from 27 interviews with local walrus hunters as part of a larger project on walruses and population health in Nunavik (Northern Quebec, Canada). The limitations and biases detected were: (a) spatial bias towards the coast of the mapped walrus observations; (b) bias that areas free of mapped observations could either 


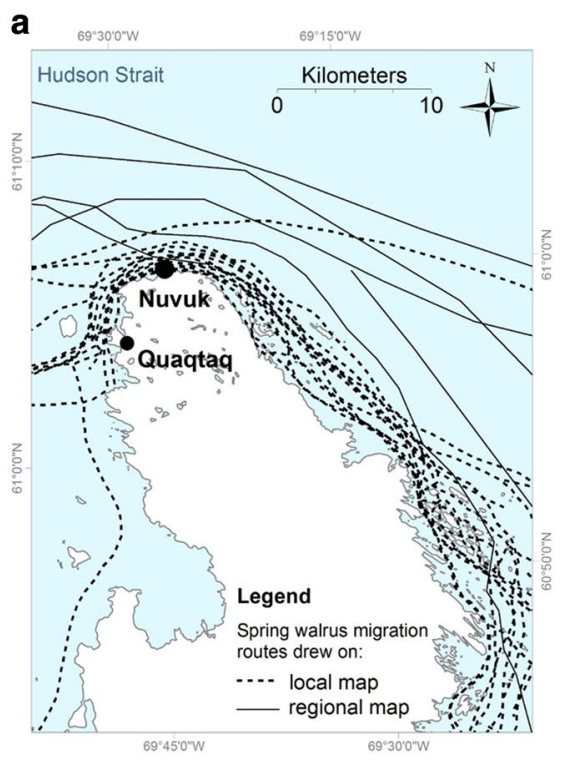

Fig. 5 The importance of map scale when documenting the migration routes of Atlantic walruses, Odobenus rosmarus rosmarus. a Map showing the walrus migration routes in summer drawn on regional map (1:2,000,000; grey full lines) and drawn on local map (1:170,000; dotted black lines) near Quaqtaq (Nunavik, Northern Quebec, Canada). A vertical line (drawn from Nuvuk point) was

correspond to absence of walruses (areas visited by hunters) or absence of data (areas not visited by hunters); (c) inter-participant variation in the quantity and diversity of mapped walrus observations; (d) limitations created by not recording the approximate number of walruses for each areas drawn, and (e) bias of creating maps with features drawn at different map scales. Although some limitations and biases have been partially reported in previous studies (Gilchrist et al. 2005; Gagnon and Berteaux 2009), no previous study has presented analyses that statistically demonstrate the biases created by common LEK methods, or rarely proposed solutions to address them.

First, we showed that by defining and adding to maps the geographic limits of participants' common areas of observations, defined for each time period and season, the following biases were identified and could be avoided: (a) the observation that over time walruses have changed location, when in fact it was the hunting locations that have changed over time; (b) that walruses used the same migration routes in the fall as those in the summer, when in fact hunter observations in the fall were scarce or non-existent; and (c) that walruses were concentrated along the coast, when in fact it was the observations of hunters that were concentrated along the coast. Thus, it is important to acknowledge that LEK on walrus migration can represent the path taken by only a portion of the population, specifically those walruses travelling within participants' common areas and months/years of observations, and not all animals. Lewis b

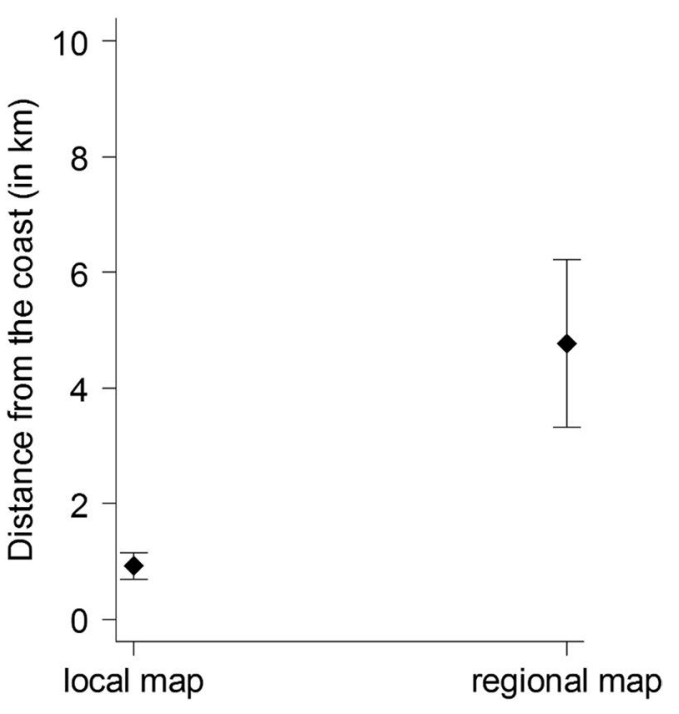

used to calculate the distances between the coast and each migration route drawn ( $n=17$ distances measured). b Differences between local and regional maps in the estimated distances from the coast of walrus migration routes. The means are 0.92 and $4.77 \mathrm{~km}$, respectively, for regional $(n=12)$ and local maps $(n=5)$ (Wilcoxon test: $W=7$, $p=0.02)$. Bars $\pm \mathrm{SE}$

et al. (2009) showed that while $76 \%$ of telemetry data for 30 belugas (Delphinapterus leucas) were located within $15 \mathrm{~km}$ offshore, only $17 \%$ of TEK data indicated offshore locations. To gather knowledge on walrus movement and distribution outside of participants' common areas and months/years of observations, other techniques such as satellite telemetry or a combination of aerial and acoustic surveys can be used (Fernandez-Gimenez et al. 2006; Lewis et al. 2009). Additionally, by defining and adding to maps the geographic limits of participants' common areas of observations, we were able to distinguish areas that hunters typically visited and did not see walruses (absence of walruses) from areas that hunters never or rarely visited (absence of data). The risk of maps, which does not include the limits of participants' common areas of observations, is that areas without mapped observations may be interpreted as being free of wildlife, which in turn could be considered as prospective areas for development or areas of unimportant habitat for a particular species. The internal validation conducted through group workshops in each community highlighted the desire of participants to include these limits on maps and in analyses and increase the accuracy of the data they shared. The inclusion of these limits in the dataset was not imposed by the researchers, but rather requested by the participants themselves. Furthermore, at the end of the validation workshops, participants requested to make it clear in the reports/papers that the maps created represent the knowledge of a subset of all local hunters from four 
communities in Nunavik, and not all local knowledge for the region. In this sense, this study highlights the desire of participants to report only what is within the bounds of their observations, rather than provide speculative information from areas with which they are less familiar. We argue that in combination with identifying and employing specific criteria for the recruitment of study participants (Davis and Wagner 2003), it is essential to record these limits when mapping LEK. To this end, we propose the following guidelines: (1) record the geographic limits of participants' common areas of observations at the end of the interviews or focus groups, and validate those during subsequent internal validation workshops; (2) record the geographic limits of participants' common areas of observations for each season; (3) record the geographic limits of participants' common areas of observations for each time period (e.g., 1940s-1990s) unless there is no change in observations over time.

Second, we observed that the age of participant did not influence the number and diversity of mapped observations they provided. Instead, participants with greater experience in walrus hunting (corresponding to those who had been walrus hunting more than ten times during their life) provided a higher quantity and diversity of information related to walruses on the maps. These results highlight the importance of including the number of hunting trips or some measure of experience in the criteria used to select participants. Our results also showed that although Elders are often preferred participants for these studies, it is important to identify and use criteria focused on experience and frequency of observations in selecting participants. These criteria can act as proxy measures of individuals' expertise. Additionally, we observed that compared to other communities, participants from Ivujivik provided greater quantity and diversity of mapped observations, suggesting a greater expertise in walrus hunting of this community. It is also possible that on Nottingham and Salisbury Islands, where Ivujivik hunters hunt walrus, there was a higher number of groups of walruses concentrating at different locations and performing different behaviors. In general, it is assumed that the quantity of the information provided by participants depends on the expertise of the participant and his/ her community (Davis and Wagner 2003; Gilchrist et al. 2005).

Third, we showed that the size of the walrus areas drawn were not proportional to the approximate number of walruses reported in those locations, as could be incorrectly interpreted by readers and those interacting with LEK-generated maps. We showed that this bias could be reduced by documenting the approximate number of animals observed in a given area. At this point it is difficult to explain the inter-participant variability in the sizes of the walrus areas drawn (those drawn during interviews and validated during workshops). This requires further exploration in future work. However one could hypothesize that interparticipant variability in the sizes of walrus areas drawn are the result of: (1) an overestimation or underestimation by some participants of the extent of the areas where walruses have been observed; (2) inter-participant variability in the geographic limits of their common areas of observations; or (3) inter-participant variability in the precision of the locations provided (e.g., points vs large areas for the same observation). Lastly, although careful adjustments and standardization would be needed to obtain more accurate estimates of both area sizes and number of walruses (e.g., obtain an interval of confidence for the approximate numbers provided), by having an estimate of the number of walruses observed in each walrus area drawn, as well as an estimate of the sampling effort of each hunter or hunting expedition, it might be possible to estimate mean local abundances of walruses. A similar approach was developed and applied to estimate mean local abundance of the Greek tortoise (Testudo graeca) in Spain, which represented a more economical approach to population monitoring than more standard line-survey techniques (Anadón et al. 2008). Note that while estimated mean local abundances might be possible to obtain for walruses in Nunavik, which were generally reported in groups of less than 50, it might not be the case for large aggregations of walruses (e.g., hundreds of stranded walruses observed in other regions). Finally, calculating mean local abundances might support the argument for greater inclusion of LEK in wildlife management (Gilchrist et al. 2005; Mauro and Hardison 2011).

Fourth, we provided further evidence of the importance of map scale when mapping LEK by highlighting the differences in distances from the coast in walrus migration routes drawn for the same region on different scale maps. As predicted, the migration routes drawn on regional maps $(1: 2,000,000)$ were significantly further from the coast than those drawn on local maps $(1: 170,000)$. In reality, all migration routes drawn on the regional map were situated outside of the geographic limit of participants' common areas of observations, highlighting the overestimation, rather than underestimation, of the distances from the coast when drawing on the regional map compared with the local map. When discussing with participants during the internal validation, the variations in the distances from the coast of the walruses' migration routes drawn on regional maps compared with those drawn on local maps, participants explained that, although the lines drawn on the regional map provided information on the general directions taken by walruses during their migration, those lines were less precise than those drawn on local maps. Although one can argue that the unfamiliarity with certain map scales could be a potential confounder for participants to 
evaluate distances (i.e., maps printed by the government are generally $1: 250,000$ and 1:50,000), this is unlikely the case here as the participating communities have been involved in several LEK projects (e.g., belugas, bowhead whales) that have used similar map scales in their data collection (Chris Furgal, unpublished information).

To conclude, by being critical of the methods we used, and by identifying and exploring the biases they potentially introduced, we were better able to examine and implement strategies to address them. We argue that these strategies will help to create more reliable datasets that more accurately reflect hunters' knowledge and observations of species in the future and help such studies meet the standards of good qualitative research methods that exist (Huntington 2000; Davis and Wagner 2003; Furgal and Laing 2012). We hope that this critical examination of methods will also help to increase widespread trust and confidence in these datasets as a valuable source of knowledge for wildlife management and decision-making.

Acknowledgements We thank the communities of Kangiqsualujjuaq, Quaqtaq, Ivujivik, Inukjuak and their Local Hunting Fishing and Trapping Associations, Northern Villages and Landholding Corporations; all the Inuit involved in the project including the local collaborators particularly Robbie Ningiuruvik, and all the participants, who agreed to be interviewed for the larger project. Participants in Quaqtaq were: David Okpik, Charlie Okpik, Bobby Nakoolak, Eva Deer, Louisa Kulula, Susie Aloupa-Itigaituk, Richard Page, Johnny Oovaut, Willie Kaukai, Willie Jararuse; in Ivujivik: Quitsak Tarriasuk, Lucassie Kanarjuaq, Tivi Kiatainaq, Mattiusi Iyaituk, Adamie Kalingo, Ali Qavavauk, Charlie Paningajak, Saima Mark, Susie Kalingo; in Inukjuak: Simeonie Ohaituk, Jobie Ohaituk, Jusipi Nalukturak, Davidee Nastapoka, Shaomik Inukpuk, Lucy Weetaluktuk, Daniel Inukpuk; in Kangiqsualujjuaq: Sammy Kokkinerk, Sammy Unatweenuk, Paul Jararuse, Bobby Baron, Paul Toomas, Tivi Etok, Kenny Angnatuk, and one anonymous participant; Pasha Puttayut from Quaqtaq for providing maps of the area in Inuktitut; Manon Simard, Bill Doidge and Michael Kwan from the Nunavik Research Center (Makivik Corporation) and the Kativik Regional School Board (Gilles Dubé, Tommy Arnatuk, Douglas Stewart, Therese Pelletier, Nancy Etok) for their help with the logistics; Kaitlin BretonHoneyman for her input when mapping participants' common areas of observations; Lanna Desantis, Debbie Jenkins and Philip Bertrand for their input in raising some of the key challenges presented in this paper; Thomas Doniol-Valcroze for his assistance with government paperwork; Noah Ben-Ezra for his assistance with formatting the paper. We are grateful to the different funding bodies including the Nunavik Marine Region Wildlife Board, Department of Fisheries and Oceans Canada, Foreign Affairs and International Trade Canada, Trent University NSERC Internal Grant, Symons Trust Fund for Canadian Studies.

Open Access This article is distributed under the terms of the Creative Commons Attribution 4.0 International License (http:// creativecommons.org/licenses/by/4.0/), which permits unrestricted use, distribution, and reproduction in any medium, provided you give appropriate credit to the original author(s) and the source, provide a link to the Creative Commons license, and indicate if changes were made.

\section{References}

Anadón JD, Giménez A, Ballestar R, Pérez I (2008) Evaluation of local ecological knowledge as a method for collecting extensive data on animal abundance. Conserv Biol 23:617-625. doi:10.1111/j.1523-1739.2008.01145.x

Azzurro E, Moschella P, Maynou F (2011) Tracking signals of change in Mediterranean fish diversity based on local ecological knowledge. PLOS One 6:1-8. doi:10.1371/journal. pone. 0024885

Berkes F, Colding J, Folke C (2000) Rediscovery of traditional ecological knowledge as adaptive management. Ecol Appl 10:1251-1262. doi:10.1890/1051-0761(2000)010[1251:ROTE $\mathrm{KA}] 2.0 . \mathrm{CO} ; 2$

Crawley MJ (2007) The R book. Wiley, Chichester

Creswell JW (2009) Research design—qualitative, quantitative, and mixed methods approaches, 3rd edn. Sage Publications, Thousand Oaks

Davis A, Wagner JR (2003) Who knows? On the importance of identifying "experts" when researching local ecological knowledge. Hum Ecol 31:463-489. doi:10.1023/A:1025075923297

Ellis SC (2005) Meaningful consideration? A review of traditional knowledge in environmental decision making. Arctic 58:6677. doi: $10.2307 / 40512668$

Fernandez-Gimenez ME, Huntington HP, Frost KJ (2006) Integration or co-optation? Traditional knowledge and science in the Alaska beluga whale committee. Environ Conserv 33:306315. doi:10.1017/S0376892906003420

Furgal C, Laing R (2012) A synthesis and critical review of the traditional ecological knowledge literature on narwhal (Monodon monoceros) in the Eastern Canadian Arctic. DFO, Canada

Gadamus L, Raymond-Yakoubian J (2015) Qualitative participatory mapping of seal and walrus harvest and habitat areas: documenting indigenous knowledge, preserving local values, and discouraging map misuse. IJAGR 6:76-93. doi:10.4018/ ijagr.2015010105

Gagnon CA, Berteaux D (2009) Integrating traditional ecological knowledge and ecological science: a question of scale. Ecol Soc 14:19

Gilchrist HG, Mallory ML, Merkel F (2005) Can local ecological knowledge contribute to wildlife management? Case studies of migratory birds. Ecol Soc 10:20

Hartwig L (2009) Mapping traditional knowledge related to the identification of ecologically and biologically significant areas in the Beaufort Sea. DFO, Canada

Huntington HP (2000) Using traditional ecological knowledge in science: methods and applications. Ecol Appl 10:1270-1274

Huntington HP (2011) The local perspective. Nature 478:182-183. doi: $10.1038 / 478182 \mathrm{a}$

Ihaka R, Gentleman R (1996) R: A language for data analysis and graphics. J Comput Graph Stat 5:299-314

Kowalchuk KA, Kuhn RG (2012) Mammal distribution in Nunavut: Inuit harvest data and COSEWIC's species at risk assessment process. Ecol Soc 17:4. doi:10.5751/ES-04893-170304

Laidler GJ (2006) Inuit and scientific perspectives on the relationship between sea ice and climate change: the ideal complement? Clim Chang 78:407-444. doi:10.1007/s10584-006-9064-Z

Larrat S, Simard M, Lair S, Bélanger D, Proulx JF (2012) From science to action and from action to science: the Nunavik trichinellosis prevention program. Int J Circumpolar Health 71:1-9. doi:10.3402/ijch.v71i0.18595

Lewis A, Hammill M, Power M (2009) Hudson Bay beluga whales (Delphinapterus leucas): a comparison of patterns found through satellite telemetry and Nunavik traditional ecological knowledge. Arctic 62:13-24 
Mallory ML, Gilchrist HG, Fontaine AJ, Akearok JA (2003) Local ecological knowledge of ivory gull declines in Arctic Canada. Arctic 56:293-299

Martinez-Levasseur LM, Furgal C, Hammill M, Burness G (2016) Towards a better understanding of the effects of UV on Atlantic walruses (Odobenus rosmarus rosmarus): a study combining histological data with local ecological knowledge. PLoS One 11:e0152122. doi:10.1371/journal.pone.0152122

Mauro F, Hardison PD (2011) Traditional knowledge of indigenous and local communities: international debate and policy initiatives. Ecol Appl 10:1263-1269

Mymrin NI, Community of Novoe-Chaplino, Community of Sireniki, Community of Uelen, Community of Yanrakinnot, Huntington HP (1999) Traditional knowledge of the ecology of beluga whales (Delphinapterus leucas) in the Northern Bering Sea, Chukotka, Russia. Arctic 52:62-70

Nadasdy P (2003) Reevaluating the co-management success story. Arctic 56:367-380

Pardo de Santayana M, Macía MJ (2015) Biodiversity: the benefits of traditional knowledge. Nature 518:487-488

Pena E, Slate E (2006) Global validation of linear model assumptions. J Am Stat Assoc 101:341-354

R Development Core Team (2015) R: A Language and Environment for Statistical Computing. Vienna, Austria : the R Foundation for Statistical Computing. http://www.R-project.org/
Seidman I (2006) Interviewing as qualitative research: a guide for researchers in education and the social sciences. Teachers College Press, New York

Service CN, Adams MS, Artelle KA, Paquet P, Grant LV, Darimont CT (2014) Indigenous knowledge and science unite to reveal spatial and temporal dimensions of distributional shift in wildlife of conservation concern. PLoS One 9:e101595. doi:10.1371/ journal.pone.0101595

Stewart REA (2008) Redefining walrus stocks in Canada. Arctic 61:292-308

Tobias TN (2009) Living proof. The essential data collection guide for indigenous use and occupancy map surveys. Ecotrust Canada, Vancouver

Turvey ST, Risley CL, Moore JE, Barrett LA, Yujiang H, Xiujiang Z, Kaiya Z, Ding W (2013) Can local ecological knowledge be used to assess status and extinction drivers in a threatened freshwater cetacean? Biol Conserv 157:352-360. doi:10.1016/j. biocon.2012.07.016

Wiles A, McEwen J, Sadar MH (1999) Use of traditional ecological knowledge in environmental assessment of uranium mining in the Athabasca Saskatchewan. IAPA 17:107-114. doi: $10.3152 / 147154699781767864$ 